\title{
Erratum
}

\section{A Thermostable Bilirubin-Oxidizing Enzyme from Activated Sludge Isolated by a Metagenomic Approach}

\author{
NOBUTADA KimURA ${ }^{1}$, and YOICHI KAMAGATA ${ }^{1}$ \\ ${ }^{1}$ Bioproduction Research Institute, National Institute of Advanced Industrial Science and Technology (AIST), Tsukuba, Ibaraki \\ 305-8566, Japan
}

Volume 31, no. 4, Page 435-441, 2016

Page 435

Year of "Published online" is incorrect. It should be corrected as follows:

incorrect: 2015

correct: 2016

This correction has been completed on the electronic file of the present paper available at J-STAGE and PMC.

The editorial board expresses sincere apology for the misprinting. 